OPEN ACCESS

Citation: Beniamino Masi (2021) Looking through the mirror: representativeness of the Italian party system before the 2018 General Election. Quaderni dell'Osservatorio elettorale - Italian Journal of Electoral Studies 84(1): 69-83. doi: 10.36253/qoe-10237

Received: December 29, 2020

Accepted: June 21, 2021

Published: July 20, 2021

Copyright: @ 2021 Beniamino Masi. This is an open access, peer-reviewed article published by Firenze University Press (http://www.fupress.com/qoe) and distributed under the terms of the Creative Commons Attribution License, which permits unrestricted use, distribution, and reproduction in any medium, provided the original author and source are credited.

Data Availability Statement: All relevant data are within the paper and its Supporting Information files.

Competing Interests: The Author(s) declare(s) no conflict of interest.

\section{Looking through the mirror: representativeness of the Italian party system before the 2018 General Election}

\author{
Beniamino Masi \\ University of Pisa \\ E-mail: beniamino.masi@phd.unipi.it \\ ORCID: 0000-0001-5568-8373
}

\begin{abstract}
The use of the Internet and communication technologies has dramatically increased in recent times. This change has affected every aspect of political life, with electoral campaigns and parties making no exception. One of the most significant advancements on the theme is the spread of Voting Advice Applications (VAAs). These tools are developed before elections to match users' policy preferences to those of the parties running. By looking at the dataset created with the answers of the users of an Italian VAA, Navigatore Elettorale, this study aims at understanding the representativeness of the six main parties running in the 2018 General Election. Through the development of a Representative Deficit Index, the study will also assess the key policy areas in which each of these parties performed best in the eyes of the electorate. The finding shows a diversified pattern of (in)successes for each of the parties, with some unexpected results.
\end{abstract}

Keywords: representation, electoral campaigns, Voting Advice Applications, political parties.

\section{INTRODUCTION}

Since the late 1980s, political parties entered a path of decreasing trust and confidence. Many reasons contributed to this decline, with the results that, today, the decline of these organisations can be seen from many different points of observation (Ignazi 2020). One of the reasons behind this drop in confidence has been explained by a process of detachment of parties from voters' social bases, whereas parties have progressively become similar to public agencies, losing their linkage with society (Mair 2013).

Political representation is usually referred to as the relationship between voters (or citizens in general) and their elected counterparts (Pitkin 1967), where the former are acting in the name or in trust of the latter. This relationship is often mediated through parties, which are supposed to act as the main link between voters and candidates or elected representatives, and when parties fail to perform this role, the whole representative circuit 
is affected. For this reason, the theme of representation, and representation of opinions and policy preferences in particular, becomes of particular interest for the understanding of this complex process of party change and party decline.

Departing from this strand of literature, the present work will assess the representativeness of parties running in the 2018 Italian General Election through a partial innovation of the methodology originally proposed by Alvarez et al. (2014) and further discussed by Bright et al. (2020). As a matter of fact, the theme has not been systematically assessed in the previous literature, while still being of great interest for the understanding of the Italian party system and politics. The Italian case is of particular interest since it has been often referred to as an important example of the decay of democracy and representation. Italian parties are fragile and, since the beginning of the so-called "Second Republic", they tend to suffer from an increasing distrust, which is reflected in membership numbers, turnout rates and party system fragmentation (Pizzimenti 2020). Trust in political parties decreased to a point that in 2018 only 5\% of Italian voters declared they trusted them. In this scenario, Italy has become the first Western country where populists gained a majority and formed a coalition government together (Garzia 2018), capitalizing on their discourse highlighting a division between the "good people" and the "corrupt elite" (Mudde 2018). Under this setting, the study of the distance between voters and parties becomes of particular interest for the understanding of the Italian party system.

Thanks to the dataset generated from the Italian Voting Advice Application (VAA) Navigatore Elettorale, we were able to calculate an index that measures the distance from each potential voter from its best-matching party or, in other words, a representative deficit. This representative deficit can be considered an indicator of the state of the Italian democracy, and as such it will help to shed some lights on the reasons behind this lack of representativeness of Italian parties in terms of issues covered during the electoral campaign.

The contribution is structured as follows. The first section will be dedicated to a discussion on the meaning of representation and the main challenges related to its analysis and conceptualization. Then, after an analysis of the advantages of using VAA data for assessing congruence between parties and voters, the second section will be devoted to a recognition of the Italian case and a discussion of some of the expectations which will guide our analysis. The third section will be dedicated to an explanation of the data and methods which we used, after which we will present our results. Our findings show a diversified pattern of congruence between parties and voters on different themes, with some unexpected results.

\section{VOTING ADVICE APPLICATIONS AND REPRESENTATION}

The term "representation" is perhaps one of the most frequently used words in political writings, but the discussion over what representation actually means came extremely late. In her archetypical work "The Concept of Representation" of 1967, Hannah Pitkin defines political representation as:

acting in the interest of the represented, in a manner responsive to them. The representative must act independently; his action must involve discretion and judgement; he must be the one who acts. The represented must also be (conceived as) capable of independent action and judgement, not merely being taken care of. (Pitkin 1967, p. 209)

This means that a representative must not represent only its electorate or constituents, but rather behave as a trustee taking care of the public interest and his or her understanding of what is good and what is not. Based on this theoretical framework, there is a continuous tension between the "trustee" model and the "delegate" model of representation, with the former acting in the name of the public interest and the latter acting in the name of those who directly elected him.

Pitkin's seminal work traced the path for almost all following studies on the idea of representation, with no substantial innovation on the core concept, but rather expanding on some aspects of it, providing additional arguments in favour of Pitkin's idea or building on the need for accountability for representatives.

What is important to note, as many studies demonstrate (for a review see for instance Ashworth 2012), is that this tension between the two models of representation can result in important differences in the way voters tend to evaluate the performances of the candidates, as some could appreciate more congruence between citizens' preferences and the policies put forward by the elected politicians, while others might prefer to look at outcomes rather than at the policies themselves (Fox \& Shotts 2009).

Many scholars seem to converge on the idea that political representation traditionally conceptualized is in crisis (see, for instance, Conti et al. 2018). Some of the indicators usually taken to assess the extent of this crisis are voter turnout, party membership, party fragmentation, levels of engagement with politics in citizens, levels of trust in politics, and many others. Since modern 
democracies have their roots in parties and representation in general, this crisis has often been referred to as a crisis of democracy in general.

The common assumption of these studies is that the ongoing decline in party membership, voter turnout, satisfaction with democracy and the recent success of anti-establishment parties are all symptoms of an ill democracy. This anti-democratic trend has recently led many scholars to talk about a "Democracy Disfigured" (Urbinati 2014), to predict the "end of representative politics" (Tormey 2015) or the "hollowing of Western Democracies" (Mair 2013).

In this scenario, most modern parties suffered a downfall of membership (Van Biezen et al. 2011), and their role has shifted from representing society to governing the state (Katz \& Mair 1995). Moreover, the growing tension between responsibility and responsiveness, and its consequent increase in the "cost of ruling" (Mair 2009), resulted in the crisis of democracy taking the form of a crisis of democratic representation.

This decline in trust in democracy and parties affected most western countries, with Italy making no exception. Indeed, the decline of confidence in parties in Italy stemmed from many different reasons but resulted in the same distrust observed elsewhere (Morlino 1996). However, the Italian case is of particular interest for the study of party representativeness, since the structural weaknesses of the party system, along with some systemic deficiencies, caused Italian parties to be generally more fragile and dynamic (Pizzimenti 2020).

However, there are indeed some clues indicating that citizens' interest in politics has not abated. The growing success of VAAs in Italy and abroad suggests that many citizens are seeking information on parties and elections and are willing to spend time to make an informed decision.

One of the ways VAAs could help to contrast the crisis of democracy is their explicit aim of matching the opinion of citizens with parties' policy positioning. This way, VAAs can help voters gather the information they need in an easy and engaging way, perhaps facilitating their vote and convincing them to cast it (Garzia 2010; Kamoen et al. 2015).

Given their way of delivering information, VAAs are useful tools for assessing the representativeness of parties and party systems. Nonetheless, the study of representation through Voting Advice Applications is not as popular as other fields of research on VAAs. On the other hand, some interest has sprouted recently and some works have been published on the matter.

In order to study representation, a flourishing body of literature takes as a source of information party man- ifestos before elections, and then compares them with surveys of public opinion on salient issues (e.g. Ezrow et al. 2010; Adams et al. 2004). The most important source for the positioning of parties through their manifestos is with no doubt the "Comparative Manifesto Project" (CMP). However, recently some scholars started to drop the classical CMP dataset in favour of VAA datasets, where users and parties are directly confronted on the same issues, with the same words and with no relevant discrepancy between parties and voters, overcoming an important limitation of the research with the CMP.

When working with VAAs and representation, the question of the validity of such studies is paramount. These applications look at party manifestos, leaders' declarations, party websites and expert surveys before the elections, and therefore they mainly focus on promises and pledges done by parties and candidates rather than policy outputs.

Voting Advice Applications suit well within most of the classical conceptualizations of representation. They deliver easy to understand information about political parties, candidates and their positions with a reliable source, which is usually accessible to all users. This is fundamental for monitoring and eventually sanctioning elected representatives with an ex-post control (the link between pledges and parliamentary behaviour), but also for a proper evaluation of candidates through an ex-ante control (Ladner 2016). Through the information they provide, they foster political representation and the whole democratic process (Fivaz \& Schwarz 2007).

As shown, the ex-post control has been thoroughly studied through VAAs, but the way through which VAAs foster an ex-ante control is still underrated and has not seen any significant work.

The link between electoral participation and engagement on the one hand, and VAA usage on the other hand, was made more clear by a work by Alvarez et al. (2014), who argued that the degree to which this relationship is true for any election utilising a VAA can be measured through what they called "representative deficit", defined as "the degree to which the party list produced by the VAA fails to match the demand: the lower the match, the higher the representative deficit, i.e. the worse a voter's issue preferences are reflected by the political supply" (p. 229). In more practical terms, the deficit is measured by calculating the degree to which the bestmatching party fails to match voters' preferences: for example, if the congruence with the best-matching party is $70 \%$, the deficit is $30 \%^{1}$. In this vision, VAAs are useful

\footnotetext{
${ }^{1}$ It should be noted that, since representation is not based only on opinions (which is the only aspect that can be measured through a VAA), it would be more accurate to call the "representative deficit" as "opin-
} 
tools not only to inform citizens about the positioning of parties, but to create personalised pieces of advice as well, giving users both the ranking of parties who match best (and worse) with their opinion, and the degree to which this match is present. Thus, data obtained through VAAs can be useful to scholars and academics to better understand party system representativeness.

Unfortunately, the concept of representative deficit has not been exploited to its potential, since it has only been utilised in a handful of studies to understand to what degree VAAs can be useful. In particular, it has been argued that VAAs are more effective to bring citizens to vote when there is a lower representative deficit (i.e. when citizens' preferences better overlap with party positions). On the other hand, a high representative deficit might foster abstention of VAA users, who might feel demotivated by their distance from every party running (Alvarez et al. 2014; Dinas et al., 2014).

The concept of representative deficit has also been used in a rather theoretical way as a means to advocate for a transnationalisation of the European voting space, because if citizens could vote for any party of any country, the representative deficit would drop by almost a quarter, helping citizens to feel closer to the European Parliament and to overcome the vision of EP elections as second-order elections (Bright et al., 2015).

With all of this in mind, this work will try to assess the representativeness of the Italian parties before the 2018 General Election through data obtained from the VAA "Navigatore Elettorale". This VAA was successfully developed in February 2018 by the Observatory on Political Parties and Representation (OPPR) from the University of Pisa in collaboration with the Dutch Kieskompas, which developed their self-titled VAA in The Netherlands and many other countries around the world. This way, the expertise of the OPPR on the Italian party system and representation was combined with the experience of Kieskompas in developing and creating VAAs, producing an instrument which was used more than half a million times by around 350.000 unique visitors.

The project gave the chance to gain access to a large anonymised dataset that could be used to study many interesting aspects of the Italian political system. By creating a Representative deficit Index (RDI) and breaking it down into different components based on the policy area, we will be able to understand how much the Italian party system was representative to the electorate as a whole.

ion representative deficit" or even "policy representative deficit" instead (Soroka \& Wlezien 2009). However, in order to follow the same path as the previous work on the matter, we decided to keep the original name created by the authors.
After a short presentation of the Italian case and the dataset used for this study, we will thoroughly discuss our methodology and describe what we would expect to find through our analysis. Then, our expectations will be confronted with our data in the final chapter, along with some considerations.

\section{THE ITALIAN CASE}

On March $4^{\text {th }} 2018$, almost 33 million of Italians cast their ballot to elect the new Parliament during the General Election. These elections are very interesting to study, as they produced a quite different picture from the elections of 2013 (for a discussion, see Chiaramonte et al. 2018).

The Parliament was elected with a new electoral law, commonly referred to as "Rosatellum", which adopted a complex mechanism. The two chambers of the Parliament were elected through a mixed system: around one third of the representatives were elected on firstpast-the-post plurality seats, while the remaining ones through proportional representation by constituents. Both houses of the Parliament were elected with a single ballot with a closed list system. Parties could form electoral coalitions and propose a shared candidate for the majoritarian seat. The parties which obtained less than $3 \%$ of the votes could not elect any representative, and the same was for the alliances which didn't reach the $10 \%$ quorum.

The elections saw two coalitions and a major standalone party. The centre-right coalition was formed by four parties (Fratelli d'Italia, Forza Italia, Noi con l'Italia and Lega), which reached $37 \%$ in total, making it the most voted coalition. On the other hand, the centreleft coalition was composed of one bigger party, Partito Democratico, three smaller parties that didn't make it to the Parliament for the proportional seats, and SVP, a small autonomist party of Südtirol. This coalition only got around $23 \%$ of the votes. The most voted party was the Five Star Movement (Movimento 5 Stelle), with more than $32 \%$ of the total votes. The only other party which managed to elect some representatives within the proportional quota is Liberi e Uguali, a left-wing federation of parties born after some splits from Partito Democratico.

The VAA created for this election, Navigatore Elettorale, was designed by taking into account the most salient issues put forward by the parties running. These issues have been broadly covered by the media and were present, in one form or another, in most platforms and/ or leaders' declarations. Among them, the most discussed ones were those of Reddito di Cittadinanza (a 
form of universal basic income), put forward by the M5S, immigration management, with a request of tightening border control by the two main right-wing parties, and a defence of Europe and Euro from the centre-left coalition led by the PD (D'Alimonte 2019; Emanuele et al. 2020)

Previous research on representation and congruence between parties and voters on policy preferences in Italy is rather scarce. The existing literature has noted that Italian parties and their voters tend to have similar positions on the left-right scale and on single policy positioning (Bellucci \& Pellegata 2017), while the ideological congruence is less noticeable on the left side of the political spectrum (Pedrazzani \& Segatti 2021). At the same time, in line with previous research, the presence of new challenger parties seem to reduce representation shortcomings only partially and only on some specific aspects (Ignazi 2020). Other studies investigated the congruence between Italian MPs and citizens, finding that legislators pay close attention to public opinion shifts and preferences of the citizens they represent, especially those in government (Visconti 2018). Nonetheless, to date the theme of representation of Italian parties has not been researched extensively yet, with most studies focusing either on the left-right spectrum, without assessing representation on single policy issues or clusters, or by taking into account MPs instead of parties as a whole. We believe that VAAs offer the chance to overcome these shortcomings, making it possible to estimate the representativeness of parties before elections on single policy issues and on thematic clusters.

The next section will introduce some of our expectations on the saliency of each of the issues we identified for the parties under analysis, which we will then try to assess based on the data we collected.

\section{Expectations}

Before looking at the data, it can be useful to express our expectations towards the data to guide us through the empirical research.

For what concerns the centre-right coalition, most of the statements of the VAA for these parties were coded based on their same common manifesto. It could be interesting to verify whether this has been a good choice for all of the parties and if they still managed to differentiate enough to represent the whole centre-right political spectrum. Thus, we want to understand whether the centre-right coalition has proved to be solid, with similar RDI scores overall, yet differently distributed among its components, as each party was aiming to a slightly different share of the electorate.
Moreover, we expect this coalition, especially FdI and Lega, to better represent its potential voters on the issues of immigration and moral issues, being these the two themes which were stressed both in all leaders' declarations and in the common manifesto. For this reason, we are interested in assessing the levels of our representative deficit for these two fields.

On the other hand, the other winner of this election, Movimento 5 Stelle, is commonly referred to as a populist party (Mosca \& Tronconi 2019). One of the main proposals of M5S was about wealth redistribution, through the creation of a "Citizens' Income", which should grant unemployed people an income from the State. It would be necessary, then, to test whether the Five Star Movement represented its potential electorate on the theme of the redistribution of wealth.

Furthermore, Liberi e Uguali, a federation of parties born only a few months before the elections, received a lot of attention from the media, without managing to have a satisfying result. The party was born following some splits from PD, mostly as a result of divergences on the theme of economic policy. For this reason, a key issue of the party was that of economic policy and wealth redistribution, over which we will focus to assess the performance of this party.

Lastly, the Democratic Party scored its lowest electoral results ever, and its coalition allies did not even make it to the 3\% quorum. The party focused most of its campaign on attributing relevance mainly to the themes of European Union and moral issues. Therefore, our fifth and last expectation is this party's representative capacity on the themes where it focused most during the 2018 campaign, the belonging to the $\mathrm{EU}$ and moral issues.

\section{MATERIALS AND METHODS}

\section{Data}

Before the 2018 General Election, the Observatory on Political Parties and Representation (University of Pisa), in collaboration with the experienced Dutch team of Kieskompas, developed a Voting Advice Application under the name of "Navigatore Elettorale". The questionnaire was composed of 32 statements against which users could express five choices on a Likert scale, ranging between "fully disagree" and "fully agree", with the chance of not expressing any opinion about the statement as well. On the other hand, party positioning was obtained through the analysis of party manifestos, parties' official websites and leaders' declarations. Missing sources for the positioning of parties were coded as "no opinion", since expert surveys have 
not been considered as reliable as the raw data obtained directly from party sources: this way, the coding process for parties could be checked in every part by all users, as each extract of text used to justify the party coding was made available to all users, whom could check the positions of all the parties and the reliability of the application.

The statements have been selected autonomously by the academic team developing the VAA, with no influence from parties or candidates. This approach differs from the one used for many other VAAs, as the statements and the coding are often proposed by parties and candidates themselves and then validated and decided by the experts. However, abstaining from asking parties directly about their opinions can have a positive effect on the validity of the research, since otherwise parties could distort their actual opinions to gain a more popular position within the VAA (Gemenis 2013).

By comparing the answers given by the users and the coding of party positions, the users received a graphical representation on a two-axis graph, where a pointer indicated their localization and the party logos indicated party positioning. The two axes of the graph represented two ideological continuums, public intervention VS free market and progressivists VS conservatives (Fig. 1). The users could also see their congruence with each party through a ranking representation, based on an Euclidean distance model (Fig. 2).

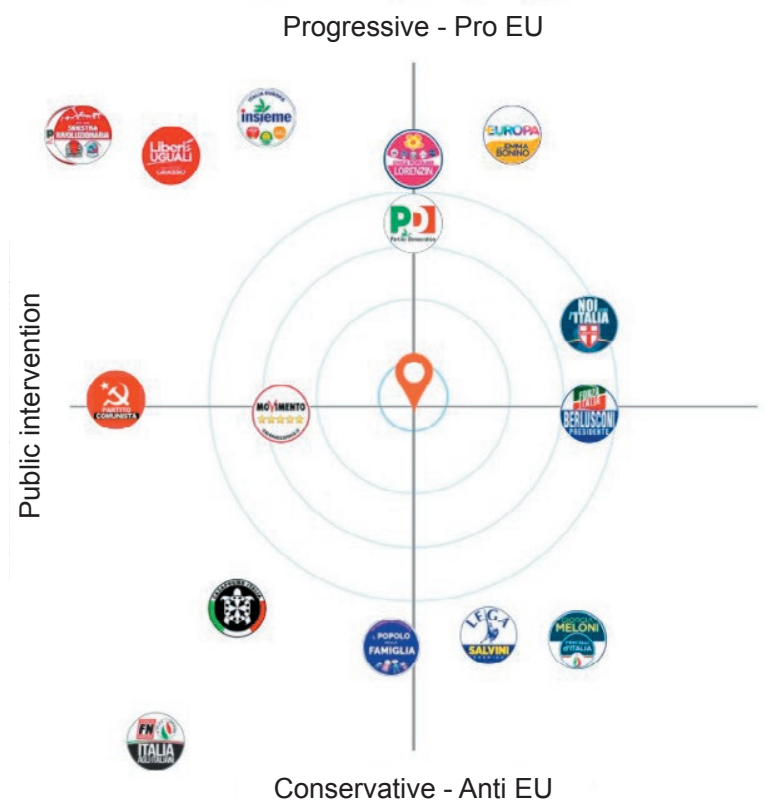

Figure 1. The graphical representation of parties and user positioning in the Navigatore Elettorale.
The congruence between users and parties was assessed by comparing the users' answer with the parties' answers for each question, and then adding or subtracting a certain number of points to the score based on the eventual proximity of the two (Table 1). The table was constructed following four rules: first, perfect agreement (e.g. both party and voter answered "agree") was considered a sign of strong congruence, thus assigning a score of 2; second, opposite answers (i.e. "completely agree" vs "completely disagree") were coded negatively with a score of -2; third; combinations of positions with the same orientation from both ends, whether positive or negative, were coded with a score of 1 (i.e. "completely agree" vs "agree" and "completely disagree" and "disagree"); last, all other cases were coded with a negative score of -1 , including those where one between the party or the user selected "neutral" as their answer. We did so because neutrality over an issue is hard to position on a scale, and we do not know whether this neutrality was due to lack of knowledge, lack of interest, inability to judge or even if this was due to disagreement with the way the question was posed. Either way, we feel like a neutral answer against a "full" answer should not be considered positively in assessing congruence, but rather a sign of distance between voter and party, whatever the reason behind it might be. Another option for coding neutral answers would have been to score "0" to every instance of neutrality both from parties or from citizens, but for the same reasons explained above, we decided not to do so. Lastly, it should be noted that even though the difference between the combinations of "agree" with "disagree" and "completely disagree" respectively are qualitatively different (and the same can be said about the combinations on the other side of Table 1), we chose to code them with the same score of -1 to make complete disagreement between parties and users (which is coded as -2) more relevant in the overall weighing of combinations.

After calculating the congruence, the score was then transposed on a $0-100$ scale, in order to have a

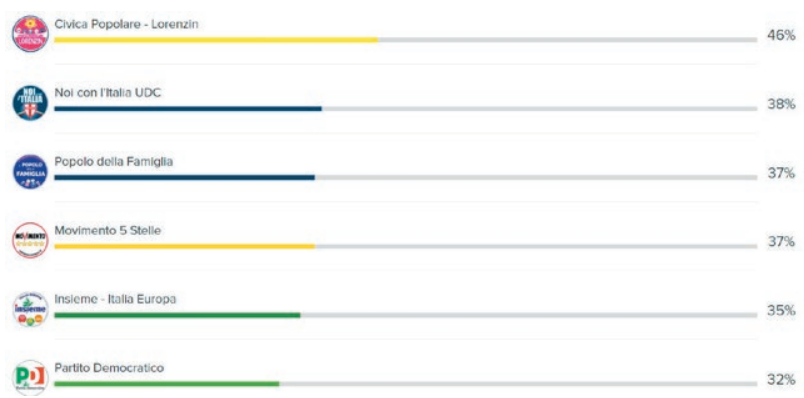

Figure 2. The ranking representation of congruence with parties in the Navigatore Elettorale. 
Table 1. Combination table for creating the Representation Deficit Index.

\begin{tabular}{lccccc}
\hline \multirow{2}{*}{ User position } & \multicolumn{3}{c}{ Party position } \\
\cline { 2 - 6 } & Completely agree & Agree & Neutral & Disagree & Completely disagree \\
\hline Completely agree & 2 & 1 & -1 & -1 & -2 \\
Agree & 1 & 2 & -1 & -1 & -1 \\
Neutral & -1 & -1 & -1 & -1 & -1 \\
Disagree & -1 & -1 & -1 & 2 & 1 \\
Completely disagree & -2 & -1 & 1 & 2 \\
\hline
\end{tabular}

percentage of the voter-party congruence. Even though we derived the concept of "representative deficit" from Alvarez et al. (2014), we used a different methodology than the one originally used by the authors, because this requires to consider only users who answered the Propensity To Vote (PTV) questions, which in our case were only around $5 \%$ of our respondents. We used a methodology, similar to the one used by Bright et al. (2020), which takes into account only the distance between the positions of the user and of the parties. Moreover, the choice seems to be justified by what Golder \& Stramski (2010) discussed about the appropriate formula for calculating congruence between a government (in our case, a single party) and citizens (i.e. what they called Manyto-One), where they suggest to calculate the distance between the single citizens and the government and calculating the mean results for an aggregate measurement. We performed the same process for each party and for each of the policy clusters we identified, assessing distances by following the rules illustrated in Table 1 as we described above.

The application gained a great deal of success and was advertised for free in many local newspapers, blogs, social media and websites. From February until the day before the election (March $3^{\text {rd }}$ ), the VAA registered more than 350.000 unique visitors. Previous VAAs in Italy for the general and European elections of 2013 and 2014 received similar numbers of visitors. The dataset was cleaned by eliminating all the cases when the user was accessing the application from outside of Italy (assessed through a geo-location variable automatically generated), respondents born from 2001 on, users who did not answer to all the questions, users who took less than 60 seconds to answer all of them (suggesting it was either a bot or a person straight-clicking through the questionnaire) and entries with the same answer for all the questions, since the questionnaire was designed to make it necessary to change the answer to some statements to have some coherence (for a discussion on the reasons for cleaning VAA data, see Andreadis 2014). After the cleaning, the dataset comprised 307.991 cases, which is still a number heftily higher than any traditional survey in Italy.

One limit of Voting Advice Applications data used for statistical research is the representativeness of their samples, since some categories tend to be over-represented (Marschall 2014). Navigatore Elettorale is not an exception: from the opt-in questions of the VAA, which were answered by less than a third of the users, there is an over-representation of males, younger people and high school graduates (Table 2). A solution for this would be to weigh cases based on census data. However, in order to maintain the larger sample of more than three hundred thousand respondents, we decided not to do so. Moreover, only around 89.000 users answered the optional demographic questions, making them only a small subset of our dataset, which could be more prone to answer these questions because of their characteristics, making it a non-representative subset as well.

The Navigatore Elettorale included 16 different parties running for a seat in both chambers of the Italian Parliament. However, in this analysis, we will be considering only the parties who managed to gather more than $3 \%$ of the total votes, which was also the threshold for gaining at least one of the proportional seats. These are also the only relevant parties in the Italian parliament today, since the other parties got just a handful of candidates elected through the majoritarian constituents ${ }^{2}$. Thus, the considered parties are (with their percentages of votes for the Camera dei Deputati) Movimento 5 Stelle (M5S, 32,68\%), Lega (L, 17,35\%), Forza Italia (FI, 14,00\%), Fratelli d'Italia (FdI, 4,35\%), Partito Democratico (PD, 18,76\%) and Liberi e Uguali (LeU, 3,39\%). In total, the users for which one of these parties was the one with the lowest representative deficit index were 211.479 , around $69 \%$ of the total users. The remaining users were closest to a party included in the VAA which is not considered in the present study, and are only con-

\footnotetext{
${ }^{2}$ These parties are Noi con l'Italia - UdC (1,30\%, 4 seats), SVP $(0,41 \%$, 4 seats), Civica Popolare (0,54\%, 2 seats), +Europa (2,56\%, 2 seats), Insieme - Italia Europa ( $0,58 \%, 1$ seat).
} 
Table 2. Distribution of users of the Navigatore Elettorale.

\begin{tabular}{llc}
\hline Gender & & $\%$ \\
\hline & Male & 61,4 \\
& Female & 38,2 \\
Education & & 89062 \\
\hline \multirow{2}{*}{ Middle school or lower } & $\%$ \\
\hline Hear of birth & Bachelor's degree & 9,3 \\
& Master's degree & 16,0 \\
& PhD & 23,2 \\
& N. & 3,1 \\
& & 88628 \\
\hline $1990-2000$ & $\%$ \\
\hline $1980-1999$ & 49,5 \\
$1970-1989$ & 22,8 \\
$1960-1979$ & 12,4 \\
1959 or lower & 9,5 \\
N. & 5,8 \\
\hline
\end{tabular}

sidered for the calculation of the general RDI in the last column of Table 4.

In the next sections, we will analyse the congruence and proximity of users with their best-matching party to understand if the Italian party system as a whole fits well with citizen preferences. Moreover, we will examine which section of each party's pre-electoral positions gained more consensus among the users who resulted closer to them. In the end, this study will be helpful to better understand present cleavages and salient issues in the Italian society and which party, if any, managed to better represent them.

\section{Method}

The Navigatore Elettorale, with its extensive coverage of all the political issues debated during the Italian electoral campaign of 2018, can be used as a very helpful tool for analysing the Italian party system.

The application contained a set of 32 statements on different topics, which are listed in Table 3. Thanks to the comparison between users' and parties' placements in all of these questions, it was possible to obtain the agreement of each user with every party or, in other terms, the representativeness of each party in terms of political opinions.

Following what Alvarez et al. (2014) defined as "representative deficit", we will hereby use such concept to create a "Representative Deficit Index" (RDI), which could be defined as the degree to which parties fail to match citizens' policy preferences and is calculated as the missing percentage from the single best-matching party of each user.

After calculating the Representative Deficit Index between each user and every party, we then split the users based on their best-matching party, and calculated the mean for each group in order to look at the mean RDI for each party. This way, we are not assuming that the best-matching party will necessarily be the party that the user will vote (as would do the selection bases on PTV questions), as we are only interested in the extent to which the Italian party system falls short in representing the range of opinions of the electorate. This enables us to compare one party to the other in terms of representativeness of opinions and pledges, shedding some light on the (non-) prevalence of issue-voting among their respective potential electorate.

To look at the matter with a potentially deeper explanatory reach, we will divide the 32 statements from the VAA into 8 clusters: immigration, European Union, regional affairs, public security, economic poli$c y$, wealth redistribution, moral values and public services. This division is illustrated in Table 3. After that, the Representative deficit index is recalculated for each cluster of statements. While recalculating the deficit, we will be still considering as the best-matching party for each user the one with the lowest overall RDI. By doing this, we hope to find a significant oscillation within each party based on the clusters. The relevance of these differences is then used to test our expectations. Such differences will explain the strengths and weaknesses of each party.

Finally, in order to understand the most salient issues and cleavages of the 2018 election and who managed to better utilise them, we will confront the results of the elections with the outcome of the analysis, offering a potential explanation for the bad results of some parties and, on the other hand, for the great results of others which did fairly good.

\section{RESULTS}

The first finding of our research is the Representative Deficit Index for the users of our VAA. By looking at the first line of Table 4, we can already note some interesting results. First of all, the RDI of LeU is around 10 points lower than average, while, on the other hand, the resulting RDI for PD is sensibly higher than the others. This means that LeU has a strong average opinion congruence with the VAA users who had LeU as their 
Table 3. VAA statements and cluster subdivision (author's translation).

\begin{tabular}{|c|c|c|}
\hline & Statements & Clusters \\
\hline 1 & Regular immigrants, even if not Italian citizens, should have the same rights and duties as other Italians & Immigration \\
\hline 2 & All children born in Italy have the right to become Italian citizens & Immigration \\
\hline 3 & Immigration significantly contributes to Italy's prosperity & Immigration \\
\hline 4 & Islam is a threat for Italian values & Immigration \\
\hline 5 & Italy should abandon the Euro & European Union \\
\hline 6 & Overall, being EU members is a disadvantage & European Union \\
\hline 7 & Overall, the adoption of the EURO represented a disadvantage & European Union \\
\hline 8 & Free circulation of goods and capitals within the EU is of vital importance for the Italian economy & European Union \\
\hline 9 & The free circulation of people within the EU should be limited & European Union \\
\hline 10 & The economic autonomy of Regions with a special statute should be extended to the other Regions as well & Regional Affairs \\
\hline 11 & Taxes collected by each Region should be entirely kept by that Region & Regional Affairs \\
\hline 12 & Restrictions to personal freedom or privacy are acceptable in order to fight crime & Public Security \\
\hline 13 & The government should spend more on law enforcement & Public Security \\
\hline 14 & Citizens should always be free to use weapons to defend their own house and/or commercial activity & Public Security \\
\hline 15 & Public expenditure for defence and armed forces should be significantly raised & Public Security \\
\hline 16 & The State should intervene the little as possible in economic issues & Economic Policy \\
\hline 17 & The number of public employees should be lowered & Economic Policy \\
\hline 18 & Companies should be freer to lay off their employees & Economic Policy \\
\hline 19 & The government's priority should be debt reduction, even at cost of cutting public services & Economic Policy \\
\hline 20 & A minimum hourly income should be introduced & Economic Policy \\
\hline 21 & The retirement age should be lowered & Economic Policy \\
\hline 22 & Wealth should be redistributed from the richest citizens to the poorest citizens & Wealth Redistribution \\
\hline 23 & Fiscal progressivity should be abolished in favour of a single rate & Wealth Redistribution \\
\hline 24 & A citizenship minimum income should be introduced & Wealth Redistribution \\
\hline 25 & Taxes on major private patrimonies should be increased & Wealth Redistribution \\
\hline 26 & Parents should be granted free choice on following the public vaccination plan & Moral Values \\
\hline 27 & All women should be granted freedom of choice on abortion & Moral Values \\
\hline 28 & Homosexual couples should have the same rights as heterosexual ones & Moral Values \\
\hline 29 & It is right for Fascist symbols to be prohibited by law & Moral Values \\
\hline 30 & Public healthcare should be more open towards the private sector & Public Services \\
\hline 31 & Public education should be free at all levels & Public Services \\
\hline 32 & Public expenditure for research should be significantly raised & Public Services \\
\hline
\end{tabular}

Table 4. Representative deficit index scores of the main parties of the 2018 Italian elections (standard deviation between parentheses).

\begin{tabular}{|c|c|c|c|c|c|c|c|}
\hline \multirow{2}{*}{ RDI } & \multicolumn{7}{|c|}{ Party } \\
\hline & FdI & FI & $\mathrm{L}$ & $\mathrm{LeU}$ & M5S & $\mathrm{PD}$ & General \\
\hline General & $35,33(6,12)$ & $38,81(5,21)$ & $34,55(6,45)$ & $28,93(7,00)$ & $37,06(5,41)$ & $41,44(6,71)$ & $35,37(6,20)$ \\
\hline Immigration & 23,91 & 40,14 & 30,47 & 30,79 & 41,85 & 40,94 & 36,39 \\
\hline EU & 35,42 & 27,11 & 28,14 & 19,40 & 33,65 & 31,63 & 28,56 \\
\hline Regional Affairs & 26,86 & 35,87 & 23,31 & 33,98 & 30,93 & 32,39 & 37,86 \\
\hline Public Security & 34,46 & 38,68 & 30,67 & 39,16 & 41,07 & 44,04 & 42,20 \\
\hline Economic Policy & 37,13 & 41,94 & 36,38 & 30,04 & 32,77 & 54,66 & 37,15 \\
\hline Wealth Redistr. & 40,42 & 44,33 & 41,23 & 35,59 & 44,02 & 47,60 & 40,97 \\
\hline Moral Values & 30,71 & 41,65 & 37,44 & 19,40 & 46,52 & 32,02 & 33,71 \\
\hline Public Services & 51,49 & 47,61 & 53,22 & 24,05 & 28,54 & 35,82 & 32,60 \\
\hline
\end{tabular}


closest party, while on the other hand the link between the opinions of PD and its potential voters is quite loose.

Other parties, such as Lega, Movimento 5 Stelle and Fratelli d'Italia, have average RDIs. Forza Italia scored an RDI around 3 points higher than that of its allies and, given the fact that most of the coding for these three parties was based on the coalition manifesto, this difference may be caused by a rather different potential ideal voter for FI and the other two members of the coalition.

When splitting the Opinion Representative deficit into clusters, the situation appears more transparent and it is not hard to see the differences between parties. The most interesting case is probably that of the centre-right coalition composed by Lega, Forza Italia and Fratelli d'Italia.

\section{The centre-right coalition}

Overall, it is not a surprise that Lega and Fratelli d'Italia, which made the issue of immigration a key one in both their campaigns, scored a relatively low RDI when looking only at immigration-related issues. Also, with FdI putting immigration at the core of their campaign, their RDI for immigration is the lowest of all parties. The same applies to the regional affairs questions, with Lega registering a quite low RDI in this matter: to understand this, it should be recalled that one of the historical political battles of Lega is that for regional autonomism and, previously, federalism (for a discussion on the evolution of the federalist agenda in the Lega, see Albertazzi, Giovannini \& Seddone 2018).

In general, Forza Italia, Lega and FdI have different deficits in all the dimensions considered, with a complex pattern of similarities and differences in all of the areas analysed. For instance, both Forza Italia and Lega have a low RDI on the matter of the EU, but for opposite reasons: the former being a pro-Euro and pro-EU party, while the latter was in favour of exiting the Euro and proposed Eurosceptic policies. On the other hand, the moderately Eurosceptic positions of the shared manifesto seem to be less liked by the FdI potential electorate in our VAA and more appreciated by the Lega's instead.

Moreover, the position of Forza Italia within the centre-right coalition is rather ambiguous, and, apart from the case of the European Union RDI, where it is in line with Lega's deficit, in all the other cases FI has a notably high deficit, especially as far as immigration is regarded (around 10\% more than Lega and 16\% more than FdI).

The case of European Union mirrors the cautious approach - without refraining from criticism - of the manifesto towards the EU, which is mainly the idea that led the previous centre-right governments supported by the Lega-FI coalition. In general, the centre-right common manifesto does not seem to have had a positive effect on Forza Italia in terms of representativeness. Based on this data, the overall RDI for all the three parties can be explained by a different cluster of issues and for different reasons, meaning that the coalition managed to represent different portions of the electorate in different sets of issues.

Interestingly, the issue of immigration has been liked by FdI's and Lega's potential voters in our VAA, but we surely cannot tell the same for Forza Italia. On the theme of moral values, the coalition's potential voters proved to be even more heterogeneous. In the end, the whole coalition resulted to be rather heterogeneous even in these key areas.

In conclusion, it is also interesting to look at the last three clusters, with the wealth redistribution RDI registering a strong disagreement for all the three parties of the coalition, where their manifesto had a general aversion towards redistribution of wealth, also because of the main proposal of the manifesto, the flat tax: in the end, based on our data this position does not seem to have been a key issue for the success of the coalition, as some evidence already suggested (Emanuele et al. 2019). The case of moral values is rather interesting, as FdI has a low deficit, indicating a strong agreement of its potential voters on the key questions of forbidding abortion, not recognising homosexual marriage and so on, which is one of the main aspects of a party which is constantly recalling the "Christian roots" of Italy. On the other hand, Forza Italia has adopted a cautious approach on the theme - which is not considered within the coalition manifesto - by not taking a stance in most of the questions analysed, with a resulting high RDI.

In the field of public services, the whole coalition manifesto is vague apart from the statement on increasing funds for the military. This vagueness resulted in a high deficit, with a peak of more than $53 \%$ for Lega.

\section{Movimento 5 Stelle}

The Movimento 5 Stelle is perhaps the most interesting party to study after the centre-right coalition: its relevance has rapidly grown since its creation less than ten years ago and it is considered by many as a populist party. However, contrary to what we could expect from a populist party, the general RDI of M5S is not far from average, with the smallest Standard Deviation among all parties after Forza Italia. 
The M5S's most liked positions were those in the field of public services, with a complex - yet well explained pattern of positions in all the statements composing the cluster. The field of regional affairs was composed of only two questions, of which the party answered only one: it would be unsafe to hazard some explanation on the whole question, but it is interesting to note that for that single question (n. 11) the agreement is quite high.

It is the key area of M5S's manifesto, wealth redistribution, to be one of the least appreciated by the party's potential voters in our VAA. This could be because of an ambiguous positioning on the big picture, with a full appreciation for a minimum "Citizens' Income" and a tepid agreement on the introduction of a flat tax, while defending the need for redistributing wealth from the richest part of the population to the poorest one. However, given the nature of the party, being a populist protest party with a great focus on the opposition between the people and the elite, it is possible that the actual proposals offered by the party were not so relevant for the decision to vote of their electors (Caiani 2019).

Similarly, a weak positioning (actually close to the one of PD) in the field of public security resulted in a high RDI, and a comparable effect is found in the cluster of immigration.

\section{Liberi e Uguali}

When looking at the representative deficit for Liberi e Uguali, it is clear that the issues of the European Union and moral values played a vital role in the support of the party.

In particular, a firm stance on the European Union as a whole, whilst not taking a stance on the Euro, has had very positive effects on the deficit, which is around 9 points lower than the general RDI. Similarly, a bold position for all the statements regarding moral values has had comparable effects on the overall agreement of the potential voters of the party.

Conversely, the party's weak positioning on matters of public security has had detrimental outcomes for the party.

In the field of economic policy, the RDI for LeU is in line with the general deficit, with no substantial gains or losses. On the other hand, wealth redistribution has an unexpectedly high RDI compared to the overall score of the party, indicating a weak congruence between the party and its potential voters on the theme. However, even if this cluster scored a RDI slightly higher than the average RDI, it should be noted that the PD has a value of more than 55 on the matter, around 15 points higher than LeU's. Therefore, we can still observe that the rea- sons for the split from PD were justified. The next paragraph will clarify the question even further.

\section{Partito Democratico}

The last party to analyse is the one with the higher representative deficit, Partito Democratico. This party was the main supporter and partner of the government before the election, with several internal divisions, which also led to the exit of the members of what later became Liberi e Uguali.

The main cause of the deficit is surely the economic policy, where the deficit reaches almost 55 points. In this field, the party's positions were in line with the former government, with the only significant new proposal of a minimum income. The need for limiting public expenditures and to reach higher flexibility on the job market, endorsed by the party, has not been seen positively by its most close VAA users.

A similar dynamic can be seen when talking about redistribution, where the party opposed a decrease in the retirement age and has not taken a firm stance on the redistribution as a whole, apart from the opposition to the proposals of a flat tax and the Citizens' Income. Also, the PD's positions on public security have been judged negatively by many users.

On the other hand, the party managed well in the key areas of its campaign, the EU and the moral values, over which most of the PD's campaign were made both by claiming the government's results on the matter and by proposing a better engagement in the future. For this reason, it is safe to assume that the party positioning on the matter has been appreciated, contrary to that on redistribution.

\section{Clusters}

Overall, if we focus on issues rather than on parties, it is clear that the issues of immigration have been best capitalised by Fratelli d'Italia, and the same goes for the European Union and the moral values themes for Liberi e Uguali, where the party recorded a surprisingly low RDI. Conversely, some themes have been badly interpreted by some parties, and an interesting example is the theme of economic policy, where PD scored an RDI 13 points higher than the second-highest, Forza Italia. Similarly, the whole centre-right coalition has a quite high representative deficit, with $12-18$ points more than $\mathrm{PD}$, on the theme of public services. 
Saliency

By only looking at these data, it is not clear yet why some parties with a generally lower RDI have had worse electoral results than others with a higher one. This is probably due to saliency reasons: not all parties are interested in the same issues in the same way. Some parties tend to emphasise certain themes, while other ones tend to blur them.

By looking at the parties' electoral results, we can try to hypothesise which were the main issues and cleavages of Italian politics in 2018 and who best managed to interpret them. However, it should be noted once again that the data we are analysing, while comprising an unprecedentedly large dataset of respondents, is still not completely representative of the overall population, so that the hypothesis we are now putting forward should be further tested and analysed in subsequent studies on the matter.

First of all, a key role for all the parties apart from Fratelli d'Italia has been played by the theme European Union, which registered the highest variation from each parties' general RDI. For example, both PD, LeU and FI have a representative deficit around 10 points lower than their average RDI. The debate over the European Union, then, certainly played a central role in all parties' campaigns.

Another important theme has been that of moral values, where all the parties have had significant shifts from their general RDI. Differently from the case of EU, however, the shifts have not always been positive, with the M5S registering a more than 9 points higher deficit.

On the other hand, the great winner of these elections has been Lega, with a growth of 13 points from the 2013 elections, becoming the unpredicted leader of the centre-right coalition. For this party, the themes of immigration, regional affairs and the EU (especially the Euro, where the party proposed to leave the common currency) have been key areas to gain their success.

On the other hand, the party that has had a major drop of voters since 2013 was Partito Democratico, which lost more than $6 \%$ from the last elections. Looking at the RDI, the themes of economic policy and wealth redistribution, together with public security, certainly had a role in the failure of the party, with the good results in the European Union issues and moral values not being enough for achieving a better result in the 2018 electoral campaign.

However, it should be noted that these relationships are still to be proved, while our data can only suggest what subsequent studies could and should build on.

\section{CONCLUSION}

The usage of VAAs around the world is spreading fast, and today at least one of them is developed for most democratic elections. The popularity of these tools made them an interesting source of data for research purposes. These applications are used by a large number of citizens, with positive effects on political knowledge, mobilization and voter turnout. The high number of VAA users makes a valid substitute for traditional surveys available, with an extremely higher number of respondents.

The usage of these tools, their effects and the data they provide has been long analysed through many different aspects. There are many angles from which scholars could potentially look at VAAs, and some of them are still to be discovered or sufficiently developed. What we looked for in this study, was indeed one of these angles: that of representation. The concept of representation is one of the most debated and difficult of political science. Following the main definitions of representation, we managed to draw a picture of political representation where the representative must act in place of someone else, while still needing to be responsive to them. Following this approach, we investigated the peculiar aspect of opinion representation, where what is important is the congruence of opinions between parties or candidates and voters. Opinion representation is fundamental for every democratic system since it is the propeller of every electoral campaign.

In order to study representation through a Voting Advice Application, we utilised data obtained from Navigatore Elettorale, a VAA launched for the 2018 Italian General Election. By matching users' policy preferences with the opinion of parties on the same matters through a VAA, we managed to shed some lights on the representativeness of the six major parties of the 2018 election and the system as a whole.

The present work tried to use this dataset to scrutinise the health of the Italian democracy and its party system. Italy is often taken as an example of an unstable party system due to its unusual number of new parties emerging rapidly and because of the rapid decline of others. At the same time, as in most Western democracies, the abstention rates are growing election after election, parties are facing a decline in membership and, more in general, citizens' trust in politics is low. Even though we need to verify whether and to what extent the Italian democracy is in crisis, we can still affirm that most of the symptoms of this illness are present.

The usage of VAAs could become in the future one of the antidotes to this crisis, as they are believed to have 
many benefits on turnout and voting behaviour in general. However, the spread of these instruments in Italy is still slow compared to some other countries, and the alleged positive effects are still to be seen on a larger scale.

On the other hand, data retrieved from VAAs can be used to assess the state of health of the Italian democracy through the analysis of how parties managed to represent the electorate opinions.

The congruence between voters' and parties' opinions was calculated based on the positional distance between the two in each question and resulted in what we defined as "Representative Deficit Index" (RDI). This deficit indicates the degree to which the best-matching party fails to represent the user over the issues considered. By splitting this deficit based on the best-matching party, we obtained the general RDI for every party, making it possible to compare one party to the other. The results indicated that one party, Partito Democratico, scored a surprisingly high deficit, while the other centreleft party, Liberi e Uguali, had a significantly low deficit instead. The other parties all had average scores, but it is worth mentioning the fact that the centre-right coalition did not have similar deficits for every party, with Forza Italia having a generally higher RDI. This indicates that promoting a common platform among the three allies had different effects on Forza Italia on the one hand, and Lega and Fratelli d'Italia on the other hand. Potential voters of the former felt less represented by the manifesto than voters of the latter.

Furthermore, to understand the reasons behind such differences in the representativeness of opinions for each party, we split once again the deficit for each party into eight different clusters of issues to address some of our expectations.

First of all, the centre-right coalition proved to be rather heterogeneous, with the deficit for Forza Italia being quite different from that of the other two parties in almost all the clusters. Moreover, what seemed like the main issues of the coalition's campaign, moral values and immigration, actually didn't meet a high opinion congruence with the parties' potential voters.

Similarly, the Five Star Movement scored a high Representation Deficit in its' main campaigning area, that of wealth redistribution, and the same happened for Liberi e Uguali. On the other hand, Partito Democratico scored a low RDI in the key areas of its electoral campaign, European Union and moral values, this time as expected.

Lastly, we laid the foundation for a subsequent study on the representativeness of the Italian party system after the 2018 elections by comparing the final percentages of Lega and Partito Democratico, the two biggest surprises of the elections, to their Representation Deficits, in order to put forward some hypothesis about which themes made their success and failure respectively.

On a more general level, past research has shown that a lower representative deficit shown by VAAs leads to a change of the party for whom one will vote in a relevant share of the users (Alvarez et al. 2014). We believe that if such a deficit is high for all parties, the user could, for the same reasons, decide not to vote at all instead of just switching party. Indeed, we can hypothesise that this is what happened for Forza Italia and Partito Democratico, whose voters in previous elections could have abstained this time due to their fairly high representative deficit.

In the last section of this study, we tried to understand what were the driving forces of a low or high representative deficit by breaking up our index based on clusters of issues, giving us the chance to gain a deeper explanatory reach.

In the end, we can see the ongoing crisis of Italian parties due to the lack of representativeness of many of them, especially the biggest ones. Even the Five Star Movement (M5S), which managed to achieve a great result both in the 2013 and 2018 elections, showed a high score in our index. This can be explained by its nature of populist party, which grew its fortune thanks to an opposition to "the elites", but can also expose the fragility the Italian party system and the whole representation mechanism in this country is.

We understand that this model, and especially the hypotheses we put forward in this last section, need further research and should be clarified through the help of more data, but we believe that the proposed methods can help to understand the current state of the Italian democracy and of any other democracy for which the data might be available. The main limitations of the present work come from the representativeness of VAA data, as some categories of voters are most likely to use them than others, impacting the external validity of any study pursued on this kind of data. Moreover, the data available made a sample stratification too costly, as the opt-in demographic and PTV questions were optional and had been answered only by a small minority of users. Nonetheless, the large dataset used in this study can be hardly found with other standard methodology, making it still worth using for explanatory analysis as this article.

In conclusion, the study of representation through VAAs proved to be a useful tool to better understand party systems, thanks to their characteristics and their reach, which is far wider than any other traditional survey. We hope that in the future more studies on the mat- 
ter will be available, since this kind of methods seems to be one of the easiest and most efficient ways to quantitatively study representation up to this day.

\section{REFERENCES}

Adams J., Clark M., Ezrow L. \& Glasgow G. [2004], «Understanding Change and Stability in Party Ideologies: Do Parties Respond to Public Opinion or to Past Election Results?», in British Journal of Political Science, 34, 4, pp. 589-610.

Albertazzi D., Giovannini A. \& Seddon A. [2018], “No regionalism please, we are Leghisti !' the transformation of the Italian Lega nord under the leadership of Matteo Salvini», in Regional \& Federal Studies, 9, 5, pp. 645-671.

Alvarez R. M., Levin I., Mair P. \& Trechsel A. [2014], "Party preferences in the digital age», in Party Politics, 20, 2, pp. 227-236.

Andreadis I. [2014], "Data Quality and Data Cleaning», in Garzia D. \& Marschall S. (eds), Matching Voters With Parties and Candidates. Voting Advice Applications in Comparative Perspective, Colchester, ECPR Press, pp. 79-91.

Ashworth S. [2012], «Electoral accountability: Recent theoretical and empirical work», in Annual Review of Political Science, 15, 1, pp. 183-201.

Bellucci P. \& Pellegata A. [2017], «Citizens' policy mood, policies and election outcomes in Italy», in Contemporary Italian Politics, 9, 1, pp. 8-29.

Bright J., Garzia D., Lacey J. \& Trechsel A. [2016], «Europe's voting space and the problem of secondorder elections: A transnational proposal», in European Union Politics, 17, 1, pp. 184-198.

Bright J., Garzia D., Lacey J., \& Trechsel A. H. [2020], "The representative deficit in different European party systems: An analysis of the elections to the European Parliament 2009-2014», in Quaderni dell'Osservatorio elettorale - Italian Journal of Electoral Studies, 83, 1, pp. 45-57.

Caiani M. [2019], «The populist parties and their electoral success: Different causes behind different populisms? The case of the five-star movement and the league», in Contemporary Italian Politics, 11, 3, pp. 236-250.

Chiaramonte A., Emanuele V., Maggini N. \& Paparo A. [2018], «Populist success in a hung Parliament: The 2018 general election in Italy», in South European Society and Politics, 23, 4, pp. 479-501.

Conti N., Hutter S. \& Nanou K. [2018], «Party competition and political representation in crisis», in Party Politics, 24, 1, pp. 3-9.
D'Alimonte R. [2019], "How the populists won in Italy», in Journal of Democracy, 30, 1, pp. 114-127.

Dinas E., Trechsel A. H. \& Vassil K. [2014], «A look into the mirror: Preferences, representation and electoral participation», in Electoral Studies, 36, pp. 290-297.

Emanuele V., Maggini N. \& Paparo A. [2019], «The times they are a-changin': Party campaign strategies in the 2018 Italian election», in West European Politics, 43, 3, pp. 665-687.

Ezrow L., Vries C. D., Steenbergen M. \& Edwards E. [2010], «Mean voter representation and partisan constituency representation: Do parties respond to the mean voter position or to their supporters?», in Party Politics, 17, 3, pp. 275-301.

Fivaz J. \& Schwarz D. [2007], «Nailing the Pudding to the Wall - E-Democracy as Catalyst for Transparency and Accountability», paper presented at the International Conference on Direct Democracy in Latin America, Buenos Aires, 14-15 March.

Fox J. \& Shotts K. W. [2009], «Delegates or trustees? A theory of political accountability", in The Journal of Politics, 71, 4, pp. 1225-1237.

Garzia D. [2010], "The effects of VAAs on users' voting behaviour: an overview» in Cedroni L. \& Garzia D. (eds), Voting Advice Applications in Europe: The state of the art, Napoli, Scriptaweb, pp. 13-33.

Garzia D. [2018], «The Italian election of 2018 and the first populist government of Western Europe». in West European Politics, 42, 3, pp. 670-680.

Gemenis K. [2013], «Estimating parties' policy positions through voting advice applications: Some methodological considerations», in Acta Politica, 48, 3, pp. 268-295.

Golder M. \& Stramski J. [2010], «Ideological congruence and electoral institutions», in American Journal of Political Science, 54, 1, pp. 90-106.

Ignazi P. [2020], «The failure of mainstream parties and the impact of new Challenger parties in France, Italy and Spain», in Italian Political Science Review/Rivista Italiana di Scienza Politica, 51, 1, pp. 100-116.

Kamoen N., Holleman B., Krouwel A., Pol J. V. \& Vreese C. D. [2015], «The Effect of Voting Advice Applications on Political Knowledge and Vote Choice», in Irish Political Studies, 30, 4, pp. 595-618.

Katz R. S. \& Mair P. [1995], "Changing models of party organization and party democracy», in Party Politics, 1, 1, pp. 5-28.

Ladner A. [2016], «Do VAAs Encourage Issue Voting and Promissory Representation? Evidence From the Swiss Smartvote», in Policy \& Internet, 8, 4, pp. 412-430.

Mair P. [2009], Representative versus Responsible Government. MPIfG Working Paper 09/8. Cologne: Max Planck Institute for the Study of Societies. 
Mair P. [2013], Ruling the void: The hollowing of Western democracy, New York, Verso.

Marschall S. [2014], «Profiling Users», in Garzia D. \& Marschall S. (eds), Matching Voters With Parties and Candidates. Voting Advice Applications in Comparative Perspective, Colchester, ECPR Press, pp. 93-104.

Mosca L. \& Tronconi F. [2019], «Beyond left and right: The eclectic populism of the five star movement», in West European Politics, 42, 6, pp. 1258-1283.

Morlino L. [1996], «Crisis of parties and change of party system in Italy», in Party Politics, 2, 1, pp. 5-30.

Mudde C. [2017], «Populism: An Ideational Approach», in C. R. Kaltwasser, P. Taggart, P. Ochoa Espejo \& P. Ostiguy (Eds.), The Oxford handbook of populism, Oxford, Oxford University Press, pp. 22-47.

Pedrazzani A. \& Segatti P. [2021], «Ideological and Policy Congruence in Italy and Spain», in Coller X. \& Sánchez-Ferrer L. (Eds.), Politicians in hard times: Spanish and south European MPs facing citizens after the Great Recession, London, Springer Nature, pp. 291-312.

Pitkin H. F. [1967], The concept of representation, Berkeley, University of California Press.

Pizzimenti E. [2020], Tigri Di Carta: Debolezza dei partiti E instabilità sistemica in italia (1994-2018), Pisa, Pisa University Press.

Soroka S. N. \& Wlezien C. [2009], Degrees of democracy: Politics, public opinion, and policy, New York, Cambridge University Press.

Tormey S. [2015], The end of representative politics, Hoboken, John Wiley \& Sons.

Urbinati N. [2014], Democracy disfigured, Cambridge, Harvard University Press.

van Biezen I., Mair P. \& Poguntke T. [2011], «Going, going, ... gone? The decline of party membership in contemporary Europe», in European Journal of Political Research, 51, 1, 24-56.

Visconti F. [2018], «The legislative representation of public opinion policy priorities in Italy», in Italian Political Science Review/Rivista Italiana di Scienza Politica, 48, 3, pp. 307-326. 